\title{
$s$ intelectuais
}

\section{do Plano Cruzado $\mathbf{I}$}

\section{Rafael Fortes 2}

\begin{abstract}
Resumo: A partir das reportagens publicadas pelas revistas Istoé e Veja sobre o Plano Cruzado, este trabalho trata do enquadramento dos membros da equipe econômica do governo Samey como intelectuais. A borda, também, a forma como se dá essa construção, discutindo critérios e características realçados pelas revistas. Por último, discute possiveis relações entre a construçẫo dos economistas como intelectuais, realizada na cobertura das revistas, e a discussão travada por pensadores como Norberto Bobbio, Antonio Gramsci, Beatriz Sarlo e Pierre Bourdieu, explorando ainda os propósitos e conse-qüências, do ponto de vista político, da visão de intelectual fomecida pelas reportagens sobre o Plano Cruzado.
\end{abstract}

\section{Palavras-chave: intelectuais, Istoé, Veja, economista, Plano Cruzado} (1986)

\begin{abstract}
A bstract: Based on the news about Cruzado Economic Plan published by two newsmagazines (Istoé and Veja), this paper deals with the framing of the members of president Sarney's economic team as intellectuals. It approaches, also, the way by which this construction is done, discussing criterion and characters enhanced by the magazines. Last, it discusses possible relations between economists' construction as intellectuals, done by the magazines' coverage, and the debate placed by authors such as Norberto Bobbio, Antonio Gramsci, Beatriz Sarlo and Pierre Bordieu, exploring the purposes and consequences, from a political point of view, of the glance of the concept of intellectual provided by the reports over Cruzado Economic Plan.
\end{abstract}

\section{Key words: intellectuals, Istoé, Veja, economist, Plano Cruzado} (Cruzado Economic Plan)

\section{1} de Pesquisa em Comunicação da Região Sudeste (Sipec) da Intercom (Sociedade Brasileira de Estudos Interdisciplinares da Comunicação), em dezembro de 2004.
2

em Comunicação (Universidade Federal Fluminense/UFF), professor da Unesa/RJ e mestre pelo Programa de Pós-Graduação em Comunicação (PPG CO M/UFF) em 2004 com a dissertação A torcida "precisa e imparcial": Istoé, Veja e o Plano Cruzado. E-mail: raffortes@hotmail.com
So b to dos os aspectos, olhando-se o problema de uma maneira geral, a reforma econômica de Samey representa uma audaciosa e competente tentativa de saneamento de uma desordem já velha de quase dez anos. Tecnicamente, parece claro que a reforma está concebida de tal forma que pode dar certo. (Carta ao Leitor [editorial]. Veja n. 913, 05/03/1986, p. 19, grifos meus).

N ossa discussão sempre teve um caráter acadêmico. Fora algum palavrão, tudo era dito em termos científicos. A pud Aluizio M aranhão e A scânio Seleme. ("A musa dos cruzados". Istoé n. 482, 19/3/1986, p. 19. Delfim Netto, sobre as divergências com Maria da Conceição Tavares) 


\section{Introdução}

Em 28 de fevereiro de 1986, em meio a uma inflação de cerca de 15\% ao mês, o presidente José Sarney lançou o Plano Cruzado. 0 objetivo principal era derrubar a inflação, através da desindexação da economia. 0 Cruzado alterou toda a estrutura econômica do país, da dívida externa ao preço do maço de cigarros no varejo. M exeu em tudo no cotidiano dos brasileiros, alterando moeda, preços, salários, dívidas. Seu principal componente era o congelamento de preços.

Fruto de elaborada teoria macroeconômica, desenvolvida principalmente pelos economistas Pérsio A rida e André Lara Resende (o primeiro era assessor do então titular da Secretaria de Planejamento, ministro João Sayad; o segundo, um dos diretores do Banco Central), o pacote econômico teve enorme repercussão na imprensa de todo o país. Notadamente no início, quando o plano foi aclamado pela população, era preciso revelar quem eram aqueles novos heróis - aqueles mágicos que tinham acabado com a inflação. 0 jornalismo não se furtou a este papel. Este trabalho busca identificar, na cobertura do Plano Cruzado, elementos que apontem para uma classificação dos membros da equipe econômica do governo Sarney como intelectuais.

0 objeto empírico é formado pelas edições das revistas semanais Veja e

0 "Plano Cruzado" (denominação que se popularizaria nas semanas seguintes), como já foi dito, foi anunciado pelo presidente José Sarney em 28 de fevereiro de 1986, por meio de cadeia nacional de rádio e televisão. As edições de Veja e Istoé datam de 5, 12, 19 e 26 de março de 1986.

\section{O s Intelectuais do Plano Cruzado}

\section{0 "G rupo da Unipuc"}

É desta fo rma que Veja caracterizo u os economistas que formularam o Plano Cruzado. 0 fato de formarem um grupo é a primeira característica marcante da maneira como os criadores do Plano Cruzado foram apresentados nas duas revistas semanais. A mbas, aliás, embora dessem espaço a uma ou outra divergência pontual entre os economistas, descreveram o grupo como fundamentalmente coeso, no aspecto interno. Esta coesão inicial é confirmada em depoimentos posteriores de alguns dos economistas (cf. Solnik, 1987).

Dentro do material empírico pesquisado, merece destaque, no que diz respeito ao objeto deste trabalho, a reportagem "O G rupo da U nipuc", publicada por 
4 Ainda que Istoé de vez em quando lançasse mão do recurso, 0 próprio uso de nota de rodapé é algo inusitado no jornalismo, o que dá certo destaque ao fato de a revista listar os nomes dos sete economistas e os órgãos governamentais em que trabalhavam.
Veja (Veja n. 914, 12/3/1986), que traça um perfil do grupo de economistas que elaboraram o Plano Cruzado. Publicada em meio a várias outras reportagens sobre o plano econômico, esta se encontra sob uma rubrica bastante peculiar: Autores. Fala dos gostos pessoais, do estilo de trabalhar, da forma com que cada um dos economistas lidou com a pressão e o sigilo em que tiveram que elaborar o pacote econômico. Ainda que busque desvendar preferências pessoais dos economistas, prima por apresentá-los como um grupo, como também destaca-se no subtítulo: "A equipe de economistas de hábitos moderados que revolucionou o cotidiano dos brasileiros" (Veja n. 914, 12/3/1986). Para Veja, os membros do grupo eram João Manuel Cardoso de Mello, Pérsio A rida, Luiz Gonzaga de Mello Belluzzo, Andrea Calabi, Luiz Carlos Mendonça de Barros, Edmar Bacha, Francisco Lopes, Fernão Bracher e André Lara Resende - todos eles economistas. Istoé (M atos \& Ribamar, 1986) apresenta praticamente a mesma equipe, apenas excluindo Francisco Lopes e Femão Bracher. Diferentemente de Veja, Istoé não chegou a destacar o grupo em uma reportagem à parte - mas falou dele logo no segundo parágrafo da primeira reportagem sobre o plano, e, embora os nomes apareçam no rodapé $\mathbf{4}$, a revista fez questão de listar a equipe completa.

\section{- O s elementos de coesão do grupo}

0 segundo aspecto da referência aos economistas diz respeito aos elementos que conferem coesão ao grupo. 0 primeiro elemento é óbvio: todos eram economistas e seus encontros tinham um objetivo comum - a elaboração de um plano econômico que desse fim à inflação. 0 segundo elemento destacado pelas revistas semanais é o trabalho incansável levado a cabo por eles. 0 grupo foi caracterizado como obstinado em sua dedicação à feitura do plano:

[...] as reuniões se intensificaram, tanto no 50 . andar do M inistério da Fazenda como no Planalto e no Alvorada, sempre avançando madrugada adentro. (M atos \& Ribamar, 1986)

0 planejamento técnico da martelada na inflação começara em setembro passado, e depois das eleições de 15 de novembro tomou-se uma atividade regular para alguns técnicos de elite, marcada por longas discussões, geralmente nas noites de terça-feira, protegidas de vazamentos na discrição oferecida pela residência oficial do presidente do Banco Central, Fernão Bracher. (M atos \& Ribamar, 1986: 18)

0 segundo trecho acima indica o terceiro fator de coesão, tratado como algo notável em várias passagens: 0 sigilo mantido pela equipe.

No ambiente secreto que foi mantido durante a elaboração do pacote, cada iniciativa isolada que o govemo adotava para a economia podia ajudar o plano geral sem a interferência de ninguém. (M atos, 1986:20)

As reuniões e a gestação das medidas econômicas não eram conhecidas sequer pelos familiares e amigos:

O s economistas que fizeram o pacote tiveram de esconder de suas famílias o que estavam fazendo para que o plano não vazasse. "Fiquei no escuro como todo mundo", diz a jornalista Andrea Bacha, 33 anos, da Rede Globo, casada com 0 economista Edmar Bacha, presidente da Fundação do Instituto Brasileiro de G eografia e Estatística, IBG E. (M atos, 1986:20) 


\section{- Características individuais}

Não obstante terem sido apresentados como um grupo coeso, os economistas também têm, cada um, características únicas. A já mencionada reportagem "O grupo da Unipuc" faz justamente isto: apresentar ao leitor os economistas que elaboraram o plano, tanto no que diz respeito à afinidade e amizade entre si (o que inclui, entre outros aspectos, identificação profissional e teórica), quanto em seus gostos pessoais, atividades de lazer e hábitos familiares.

Como exemplo das duas abordagens - a técnico-profissional e a pessoal -, destaco a figura de Pérsio A rida. Do grupo de economistas que prepararam 0 pacote econômico, A rida foi o que teve maior destaque. $N$ as revistas pesquisadas, há fotos suas em todos os exemplares de Veja e em um de Istoé. E o que estas reportagens dizem sobre 0 economista?

No aspecto profissional, Arida é descrito como "o principal cérebro das modificações" (M atos \& O liveira, 1986:19). N as matérias que discutem aspectos do plano, Arida é citado inúmeras vezes, normalmente fornecendo explicações técnicas, seja para responder a dúvidas ou críticas. Assim como outros economistas do grupo, ele é citado como um dos pupilos da economista M aria da Conceição Tavares, que ganhou grande destaque como defensora do Plano Cruzado (este assunto será discutido adiante) (Maranhão \& Seleme, 1986:19). A lém disso, foi 0 assessor escolhido por João Sayad quando o presidente Sarney pediu ao ministro que enviasse alguém a Israel para estudar o plano de combate à inflação do país. Embora a reportagem apresente todos os economistas do grupo como intelectuais - usando, inclusive, o próprio termo intelectuais para se referir a alguns deles -, mais uma vez 0 destaque é Pérsio A rida:

\footnotetext{
(...) Pérsio A rida - que divide com André Lara Resende 0 apelido de Larida -, assessor da Secretaria de Planejamento da Presidência, a Seplan, é um intelectual com jeito de intelectual de caricatura. Franzino, ascético, ele gosta de fazer cálculos matemáticos, estudar Filoso fia e escrever ensaios de teoria econômica - inclusive em alemão, um dos seis idiomas que domina. (...) A fama de "geniozinho" acompanha A rida (...) desde os tempos em que (...) militava na organização terrorista Vanguarda Armada Revolucionária-Palmares. (Veja n. 914, 12/3/1986, p. 42).
}

Na mesma página, uma foto do economista traz a legenda: "Pérsio A rida: o 'geniozinho'". Como se vê, A rida é uma espécie de personificação - de certa forma, um estereótipo - das características atribuídas pela imprensa aos economistas que pensaram e escreveram o plano. Em vista disso, sua dedicação ao trabalho também foi destacada:

\footnotetext{
"U ma hora de trabalho em casa no domingo, sem telefones tocando a cada minuto, rende tanto quando 4 horas num dia de semana", compara Arida, que costuma trabalhar também nos fins de semana. Caseiro, tem tanta aversão a festas e encontros sociais que mandou sua secretária na Seplan providenciar uma resposta padrão a convites desse tipo. (Veja n. 914, 12/3/1986, p. 42).
} 
$N$ ão por acaso, tamanha devoção pelo trabalho fez com que seus gostos pessoais e atividades preferidas de lazer - a perspectiva pessoal de que falei acima - fossem os menos destacados na reportagem, surgindo, como nos trechos acima, em meio à preferência pelo trabalho - corroborada pelo uso do adjetivo ascético para caracterizá-lo.

\section{O s economistas como intelectuais e técnicos}

Neste ponto, merecem destaque duas reportagens. A primeira, novamente, "O grupo da U nipuc", publicada por Veja. A segunda, "A musa dos cruzados", matéria de capa de Istoé sobre a economista Maria da Conceição Tavares, do PMDB.5 (Maranhão \& Seleme, 1986: 18-21). Embora não tenha participado da formulação do plano econômico, Conceição foi consultada pelos economistas às vésperas do lançamento, para que tomasse conhecimento das medidas, pois sua ajuda e aprovação eram consideradas fundamentais - tratava-se de uma economista famosa, influente, polêmica e integrante do PMDB, além de ser "alguém que se comunica com a sociedade" (M aranhão \& Seleme, 1986: 19). Conceição Tavares teve atuação decisiva na defesa do pacote frente às críticas.

Em ambas as reportagens, o termo intelectual aparece numerosas vezes, como mencionei anteriormente. É assim que os economistas são caracterizados. A doram ler livros, mas não são intelectuais generalistas. São técnicos, que viajam (à Argentina e a Israel, por exemplo) para pesquisar pacotes econômicos, trabalham madrugada adentro fazendo contas com a calculadora, elaboram complicadíssimas teorias econômicas, publicam livros.

A final de contas, parte deles é oriunda do

(...) Departamento de Economia da PUC, primeira fábrica de pensamento a destilar a idéia da reforma do cruzado em estudos e seminários promovidos por Carneiro, Francisco Lopes, André Lara Resende, Pérsio Arida e Eduardo M odiano. (M aranhão \& Seleme, 1986: 19 - grifos meus).

O s trechos grifados indicam a sólida instrução técnico-teórica dos economistas. Meses depois, uma reportagem anunciando uma pesquisa em habitação popular realizada por especialistas da U nicamp começava assim:

A clamada fonte de teses acadêmicas e famosa pela safra de economistas que formeceu
à Nova República - entre eles João M anuel Cardoso de M elo e Luiz G onzaga Beluzzo,
co-autores do pacote do cruzado -, a U niversidade Estadual de Campinas (U nicamp),
a 100 quilômetros de São Paulo, penetra ago ra na área da habitação popular,
sugerindo uma alternativa correta de construção. ("O pção de moradia", Istoé n. 495 ,
18/6/1986, p. 80).

Uma das principais universidades do país é apresentada através da economia, ou seja, é a presença de "pais do cruzado" em seus quadros que funciona como principal referencial na explicação sobre a universidade oferecida aos leitores. A formação universitária e 0 fato de persistirem no mundo acadêmico (boa parte dos economistas mencionados, incluindo Conceição, são professores universitários) credenciam os autores do plano como economistas técnicos e competentes. Aparecem nos textos expressões como "mundo acadêmico" e "concurso para professor titular", normalmente difíceis de se encontrar em textos da imprensa grande. Em uma passagem, Francisco Lopes é chamado de "um dos arquitetos da reforma" 6 . (M aranhão \& Seleme, 1986: 19). 
A forma como esse argumento da técnica foi contraposto ao da política será analisada adiante.

Conceição, por sua vez, funciona como uma espécie de avalista dos criadores do plano: "(...) a economista de 55 anos emocionou-se ao vivo, via Embratel, ao enaltecer a competência e dignidade de economistas de uma geração que ajudou a formar." (Maranhão \& Seleme, 1986: 18).

A importância de seu papel foi reforçada justamente pela capacidade da economista de se comunicar com a sociedade, superando a notória barreira entre esta e a universidade: "0 que ela mais quer no momento é voltar para o seu mundo acadêmico, que, na sua visão, nenhuma semelhança guarda com um gueto intelectual." (M aranhão \& Seleme, 1986: 19).

\section{- A popularização dos economistas}

Todavia, houve um esforço de aproximar estas figuras tão ímpares do cidadão comum, ou melhor, do leitor de classe média, público-alvo por excelência das revistas semanais de informação. Este é claramente o foco central da já extensamente mencionada reportagem "O grupo da Unipuc" (e por isso, mais uma vez, cabe fazer menção a ela), o que possibilita uma segunda leitura do já citado subtítulo: "A equipe de economistas de hábitos moderados que revolucionou a economia" (Veja n. 914, 12/3/1986, p. 42). Logo a seguir, a reportagem começa assim:

\footnotetext{
"M ané" adora doces, fica em casa de pijama e chinelos e detesta fazer exercícios. Já o "Professor" capricha no vestuário e gosta de ficar até tarde em restaurantes. Sempre que pode, "Tancredão" passa os fins de semana pescando, enquanto Andrea pratica equitação e Chico toca guitarra numa banda de jazz. André e Pérsio pensam de maneira tão semelhante que suas teses ganharam um apelido comum ao nome de ambos, "Larida" - ainda que o primeiro seja fanático por corridas de Fórmula 1 e 0 segundo prefira consumir suas horas livres escutando música clássica. Esses senhores de hábitos pacatos possuem quatro pontos em comum: freqüentaram majoritariamente os cursos de Economia da Unicamp ou da PUC do Rio de Janeiro, detestam Brasília, trabalharam num ritmo febril nas últimas semanas e, armados apenas de calculadoras, tabelas e máquinas de escrever, perpetraram a maior revolução jamais ocomida na economia brasileira. (Veja n. 914, 12/3/1986, p. 42).
}

Embora constitua uma longa citação, o parágrafo de abertura da matéria foi colocado por inteiro por permitir duas importantes inferências. A primeira, somada a uma segunda leitura do subtítulo, corrobora o que foi dito anteriormente: tenta-se aproximar os hábitos dos economistas daqueles do brasileiro de classe média (na medida do possível, é bom que se diga, pois a prática de equitação e a audição de música clássica, por exemplo, não estão entre as atividades usuais dos brasileiros de classe média), a começar pelos apelidos, que posteriormente são explicados durante 0 texto $\mathbf{7}$. A segunda inferência da passagem corrobora a análise feita anteriormente (no item 2.1.1): são todos trabalhadores incansáveis, embora a maioria consiga se divertir - como foi visto, à exceção de Arida, apresentado como a personificação do cê-dê-efe.

Contudo, a popularização destes economistas claramente apresentava alguns limites, como as preferências mencionadas no parágrafo anterior. Talvez a maior barreira tenha sido (e, em certa medida, permanece até os dias atuais) 0 
8 Não foram poucos os editoriais, cartas de leitores e reportagens que, principalmente nos primeiros meses após o lançamento do Plano Cruzado, atribuíram a Sarney a estatura de Tancredo Neves e a importância, para o país, de Juscelino Kubitschek.
9 consiste de entrevistas com Dilson Funaro, João Sayad, André Lara Resende, Pérsio Arida e Luiz Gonzaga Belluzzo. A rida e Resende são veementes ao apontarem as intromissões e concessões políticas como causas do fracasso do plano, a despeito das advertências técnicas da dupla. Ainda segundo ambos, a união da equipe começou a ser desfeita logo nas primeiras semanas após o lançamento do plano, exatamente por causa de divergências sobre concessões desejadas pelos políticos e ajustes reivindicados pela dupla. (Solnik, 1987) linguajar utilizado por eles: 0 economês. Um exemplo disso está entre os poucos lançamentos editoriais comentados a cada semana nas revistas. $\mathrm{Na}$ amostra pesquisada, há um livro escrito por dois membros do grupo - fato que é singular, pois livros de teoria econômica não costumam ser resenhados por revistas como Veja e Istoé. A crítica de Inflação Zero: Brasil, Argentina, Israel, de Arida e Resende, entre outros autores, tem um título sintomático - "Economês Puro" (N ogueira, 1986) - e recomenda ao leitor que não leia a obra, pois pouco ou nada entenderia.

Como afirmei no item anterior, M aria da Conceição Tavares popularizouse mais do que os economistas que elaboraram o plano. $0 \mathrm{~s}$ ministros A Imir Pazzianotto (Trabalho) e João Sayad (Secretaria de Planejamento) também se tornaram célebres. No entanto, nenhum deles atingiu 0 sucesso do também ministro (e empresário) Dilson Funaro (Fazenda) e, em uma escala anteriormente inimaginável, do presidente José Sarney 8

\section{Economistas técnicos e políticos políticos}

$\mathrm{Na}$ amostragem analisada, a dicotomia entre do is caráteres do plano - um, técnico, e outro, político - aparece explicitada em alguns momentos. U m deles é 0 editorial de Veja, que serve de epígrafe a este trabalho: após o tecnicamente, 0 período seguinte começa com "Politicamente, (...)" (Carta ao Leitor [editorial]. Veja n. 913,05/03/1986, p. 19). Na maior parte das situações, os políticos (incluindo integrantes do governo) e críticos aparecem, nas matérias, sugerindo alterações no pacote econômico, enquanto os economistas que 0 elaboraram, utilizando argumentos técnicos, defendem que não se façam concessões. 0 próprio Plano Cruzado, quando lançado, em 28 de fevereiro, já trazia uma série de alterações "concessões políticas", segundo Istoé e Veja - em relação à concepção original da dupla Larida. Para ficar em apenas um exemplo, nela inexistia 0 abono geral de $8 \%$ concedido aos salários.

A leitura das reportagens que falam sobre a elaboração do plano revela que as divergências internas do grupo foram resolvidas através de argumentos técnicos. As concessões, quando feitas, foram determinadas por políticos superio res hierarquicamente (Pazzianotto, Sayad, Funaro ou Sarney), sempre com motivação política. As razões apontadas para as decisões de Sarney e seus ministros foram obter apoio popular ou amenizar possíveis críticas. U ma vez lançado o plano e aceitas, por parte da equipe, as decisões, todos se uniram no esforço de explicar as medidas e defendê-las frente ao público e aos críticos (políticos de oposição - e, em casos mais raros, do próprio PM DB -, à esquerda e à direita; sindicalistas; empresários) $\mathbf{9}$. Nesta tarefa, os economistas aparecem dando as explicações técnicas, ao passo que Sarney e os ministros apresentam as justificativas políticas e conjunturais. Isto não significa que o presidente e os três ministros citados acima não tenham utilizado também argumentos técnicos e econômicos. Pelo contrário: em alguns momentos, recorreram explicitamente aos formuladores do pacote:

VEJA - 0 plano cruzado é parecido com o plano austral, que levou a Argentina a um aprofundamento da recessão e do desemprego. 0 senhor não teme que isso ocorra também no Brasil?

PAZZIANOTTO - Os responsáveis pelo plano brasileiro afirmam que não existe nenhuma razão para que haja mudança substancial no desempenho da economia. (M anso, 1986: 6) 
10 Um exemplo: a reportagem "Pacote popular" relata a aparição de Dilson Funaro no Programa Silvio Santos de $16 / 3 / 1986$, para responder a perguntas sobre 0 Plano Cruzado. (Veja n. $916,26 / 3 / 1986$, p. 119).

1 Ainda assim, o uso do termo é mais no sentido de intelectual generalista que técnico (ver item 2.2). Entrevista a Artur Pereira. (Pereira, 1986: 8)

Deste modo, é possível apreender, a partir da cobertura, uma distinção entre economistas (intelectuais técnicos) e políticos (políticos). Ela se justifica na medida em que Funaro e Sayad, por exemplo, não são apresentados propriamente como intelectuais. Eles aparecem como defensores e até mesmo explicadores 10 e certos aspectos econômicos do plano, além de defensores e debatedo res políticos, mas não são considerados "pais do Plano". São mencionados como líderes da reforma, capazes de reunir uma equipe de especialistas extremamente competente, mas não como detentores do saber técnico que capacitava cada um dos economistas por eles convidados a ser considerado um dos pais ou arquitetos do plano. A única exceção é uma entrevista em que o então ministro da Justiça, Paulo Brossard, fala da "condição de intelectual" de Sarney $\mathbf{1 1}$.

Desta forma, a partir dos argumentos utilizados e da posição ocupada, é possível identificar uma dicotomia entre economistas e políticos. A divergência nem sempre é explicitada, pois muitas vezes as posições de economistas e políticos são apresentadas individual ou isoladamente. 0 espectro de posições, que já não eram uma só quando o pacote foi lançado (nem tampouco antes do lançamento), cresceu mais e mais à medida que o plano se desenrolava. M esmo entre os ministros, por exemplo, houve uma série de divergências. Em algumas ocasiões, três ou quatro posições diferentes eram levadas a Sarney, para que escolhesse o rumo a ser tomado (cf. Solnik, 1987).

\section{Notas sobre os aspectos teóricos}

Pierre Bourdieu (1998) formulou o conceito de habitus, ou seja, de como os grupos se aglutinam em torno de valores, comportamentos, costumes etc. Segundo o autor, é mais pelo habitus que por escolhas (ou vocação) que um sujeito se insere nos diversos campos da sociedade, e com eles se relaciona. É importante advertir que não se trata de um habitus monolítico: dentro dele há espaço para divergências, contestações, lutas, aproximações e distanciamentos. 0 habitus aproxima os indivíduos de um grupo, quando os comparamos com sujeitos pertencentes a outros grupos, mas também dá conta da existência de subgrupos, assim como das diversas formas de inserção dos sujeitos nos campos sociais em que atuam (quer dizer, dos quais fazem parte, conscientemente ou não). Sendo assim, talvez seja possível falar de um habitus dos economistas dentro do primeiro escalão do governo Sarney - o que, é bom frisar, não significa que os economistas compartilhem visõ es comuns acerca das diferentes questões econômicas e políticas. 0 que isto quer dizer é que, de certa forma, havia, entre os membros do "grupo da U nipuc", determinadas afinidades: um habitus que era comum a todos os integrantes e os diferenciava dos demais participantes da equipe de governo, ainda que, dentro do grupo, houvesse espaço para conflitos, divergências e diversos matizes de opinião. Mas que diferencial era este? Defendo a idéia de que se trata do saber técnico, pretensamente neutro. Voltarei a este ponto adiante.

N esta linha, cabe atentar para a advertência de Gramsci (1989), para quem a definição dos intelectuais (quem são e qual o seu papel) deve ser buscada nas relações sociais como um todo, e não em características intrínsecas do grupo (em outras palavras, do campo intelectual, da atividade intelectual). 
12 Said (1996), ao tratar do uso do idioma como legitimador de determinados pontos de vista, utiliza 0 jornalismo para exemplificar seu raciocínio. Ele destaca o peso que tem 0 que é publicado em um órgão de grande circulação - no caso do Brasil, não é difícil pensar em Veja -, pois, na medida em que tem grande inserção numa comunidade, o órgão jornalístico é reconhecido por ela.

$13 \mathrm{Na}$ época, também governador do Estado do Rio de Janeiro.

A construção e legitimação, na - e através da - mídia, dos economistas como intelectuais, sem dúvida faz parte da busca de hegemonia em torno do plano e do próprio governo Sarney. $\mathbf{Z} \mathrm{Na}$ amostragem que pesquisei, foram raríssimas as oportunidades em que houve espaço para críticas de técnicos, fossem de instituições de oposição (por exemplo, CUT e PT) ou de outros setores (FIESP, CN I, universidades). No reduzido espaço que as reportagens dedicaram a contestações, normalmente estas eram não eram feitas por técnicos, mas sim por políticos (por exemplo, os presidentes do PT, Lula; e do PDT, Leonel Brizola $\mathbf{1 3}$, ou o secretário-geral da CUT, Jair Meneghelli) usando argumentos fundamentalmente políticos. Não quero, com isso, afirmar que Veja e Istoé funcionaram como reprodutoras da visão do Executivo, até porque não é este 0 tema em discussão neste trabalho, e tal visão seria exageradamente simplificadora. O sentido é de apontar para a importância do papel da imprensa como uma das principais formas de construção (e contestação, conforme o caso) de consenso e hegemonia cultural em sociedades contemporâneas, como a brasileira. Explorar os férteis caminhos apontados por $\mathrm{G}$ ramsci para se pensar o papel dos meios de comunicação nos jogos de consenso e dissenso que se dão em busca da hegemonia (cf. Moraes, 1998), fazendo um estudo de caso do Plano Cruzado, sem dúvida é uma proposta tentadora, mas por demais longa e complexa para ser tentada aqui.

0 sentido de intelectuais técnicos utilizado neste trabalho está próximo àqueles que Bobbio caracterizou como expertos:

O s ideólogos são aqueles que elaboram os princípios com base nos quais uma ação é justificada e, portanto, aceita - em sentido forte, a ação é "legitimada" -, pelo fato de estar conforme aos valores acolhidos como guia da ação; os expertos são aqueles que, indicando os conhecimentos mais adequados para 0 alcance de um determinado fim, fazem que a ação que a ele se conforma possa ser chamada de racional segundo 0 objetivo. (Bobbio, 1997: 74-5)

No entanto, a utilidade e pertinência da conceituação de Bobbio não se limita à caracterização acima. Ele ressalta que a divisão entre ideólogos e expertos não é necessariamente excludente ou nítida, afinal, a realidade é sempre mais complexa do que as divisões ou definições (que, em certo sentido, serão sempre simplificações, portanto, incompletas) estabelecidas por teo rias ou estudos. Desta forma, embora os técnicos sejam apresentados e legitimados, nas reportagens, através de um apelo para o discurso da competência, da técnica e da qualificação

14 Nove anos depois, durante os oito anos do governo Fernando Henrique Cardoso (1995-2002), ganhava importância um outro critério de legitimação dos integrantes da equipe econômica governista (da qual fizeram parte alguns dos criadores do Plano Cruzado, como a dupla Larida): a qualificação mercadológica, ou seja, o fato de terem experiência profissional em empresas do setor financeiro, como bancos de investimento e corretoras. (acadêmica) $\mathbf{4}$, é inegável a presença de aspectos políticos em determinadas posições por eles adotadas - mesmo quando se afirmam puramente técnicas.

Como se pode perceber, retorno à questão do discurso tecnicista. A denúncia deste argumento que se pretende não-político, quando na verdade é essencialmente político, é um dos pontos centrais da análise de Sarlo (Sarlo, 2000). Referindo-se à A rgentina (num processo que tem claras semelhanças com o brasileiro), ela trata da saída dos intelectuais da esfera pública para a academia, onde "trabalham como especialistas, e não como intelectuais" (Sarlo, 2000: 167). U ma vez mais não se trata de uma divisão excludente pois, muitas vezes, "um especialista que se converte em ministro da Economia precisa de um discurso que abranja não só aquilo que é tecnicamente possível, mas também aquilo que é desejável para a sociedade" (Sarlo, 2000: 167-8). Isto não 
15 Para considerações sobre a ascensão dos expertos, cf. também Nogueira (N ogueira, 2000).

16 recorrer à lucidez de Sarlo: "Num clima em que se comemora o fim das ideologias, os especialistas encarnam a figura da história: garantem o pragmatismo e fundam um novo tipo de realismo político. Integram as burocracias estatais que, em muitos países, colocam-se acima das lealdades políticas e dos governos. São a continuidade tecno-administrativa do Estado e se consideram, como o Estado, acima dos diversos grupos sociais e seus interesses. Falam em nome de um conhecimento técnico que, como o dinheiro, não fede nem cheira." (Sarlo, 2000: 167, grifos meus) obscurece o que constitui, para a autora, o espaço por excelência da atividade intelectual: participação assumidamente política, através do debate de idéias e valores. Tal ponto de vista também é defendido por Nogueira (N ogueira, 2000), para quem "o intelectual só se realiza na política e a partir da perspectiva política". $N$ egar estes elementos significa distanciar-se da prática intelectual. Daí a crítica de Sarlo dirigir-se, não ao saber prático em si mas, sim, à ideologia do saber prático - inclusive por, muitas vezes, afirmar-se como não-ideológico.

A ascensão destes especialistas (ou expertos), em detrimento dos ideólogos, se dá à medida que os saberes de seus campos específicos se tornam mais e mais necessários à produção. 150 ra, é precisamente este o processo que ocorre com os economistas. O Plano Cruzado marca a ascensão da economia e dos economistas a uma posição de grande importância dentro da vida nacional. A economia tomou conta da política, num processo cujo auge se deu durante a Era FHC. Um processo que - é preciso acrescentar -, embora visivelmente esgotado (e de conseqüências trágicas para a esmagadora maioria da população brasileira), a despeito da retórica em contrário defendida durante a campanha eleitoral de Lula de 2002, infelizmente, não mostrou sinais de declínio no atual governo. 16

O Plano Cruzado não marcou o início da ascensão e popularização somente da economia. Numa relação direta, ao mesmo tempo contribuindo como causa e sendo efeito, o jornalismo econômico também ganhou espaço nos veículos e nas redações. A economia tomava conta da vida pública do país, e era preciso explicar as medidas econômicas à população. Isto foi feito não somente através de reportagens, mas também da crescente participação de economistas nos mais variados órgãos de jornalismo, escrevendo ou atuando como comentaristas em jornais e revistas, rádio e TV.

Ainda para Sarlo, estes especialistas "opinam como especialistas, a partir de bases acadêmicas ou das repartições do govemo, e sua opinião obtém uma aura de o bjetividade, já que é justamente a o pinião de um especialista, que se considera acima da disputa de interesses." (Sarlo, 2000: 168). E qual seria o papel do jomalismo dentro desta análise? Como já foi defendido aqui, ele participa do processo através da predileção por discursos pretensamente neutros ou técnicos, em detrimento de posições políticas ou valorativas, ou seja, com valores claramente postos - novamente a desqualificação de Leonel Brizola é um exemplo emblemático. Nas palavras da autora, "os meios de comunicação (em particular o jomalismo) acrescentam outro fio a essa trama, sobre a qual os especialistas fazem com que seus juízos pareçam o bjetivos, atribuindo objetividade à prática tecno-científica" (Sarlo, 2000: 168). So b o argumento de que constituíam um espaço aberto, os meios de comunicação se consolidaram como arena privilegiada, na qual montou-se uma grande ficção social em tomo do Plano Cruzado.

\section{Conclusão}

Neste trabalho, procurei refletir a respeito da forma como, inicialmente em virtude da popularidade do Plano Cruzado, o grupo de economistas que se reuniu para elaborar o pacote econômico foi apresentado na imprensa. A idéia que defendi é de que eles foram apresentados como intelectuais técnicos, cuja legitimidade residia no alegado caráter científico e objetivo do conhecimento que detinham. 
17 A este respeito, vale conferir a longa reportagem "Com a força do pacote", sobre 0 então recémpopularíssimo ministro Dilson Funaro. 0 trecho a seguir é emblemático, pela comparação que faz entre Funaro e os ocupantes anterio res do cargo: "Há quatro meses se poderia criticar Funaro porque ele não tinha teorias para aplicar - tinha fé. Ter fé, agora, pode ser a melhor qualidade de Funaro. A comparação dele com seus antecessores é simples. Para Roberto Campos, 2 e 2 são 4 porque em caso contrário 2 e 3 não serão 5 . Delfim N etto acredita que 2 mais 2 são 4 e acha isso absolutamente irrelevante. Mário Henrique Simonsen está convencido de que 2 e 2 são 4 porque já conseguiu provar isso. Funaro acha que 2 e 2 precisam ser 4 para o bem do país." (Veja $915,19 / 3 / 1986$, p. 38).
A primeira parte do desenvolvimento do texto deu conta do que foi publicado a respeito dos intelectuais no primeiro mês de vigência do plano econômico. Nela, primeiro tratei da caracterização do "Grupo da Unipuc", dividindo-a entre aspectos coletivos e individuais - neste caso, tomando 0 economista Pérsio Arida como exemplo. 0 plano foi apresentado como produto do trabalho de intelectuais, gerado a partir de idéias, estudos, pesquisas e debates realizados, primeiramente, dentro da universidade. Em segundo lugar, procurei identificar elementos que corroborassem a hipótese de que os economistas do "G rupo da Unipuc" haviam sido mostrados como intelectuais técnicos, decurso do qual uma das ramificações foi a popularização dos economistas. Em terceiro lugar, observei uma divisão das medidas econômicas em um lado político e outro técnico. O s articuladores políticos do plano seriam os ministros Dilson Funaro e João Sayad, com o presidente José Sarney aparecendo como uma espécie de "grande líder" que dava as diretrizes a seus subordinados (ministros), para que estes as transmitissem aos técnicos. 0 lado técnico seria formado pelos assessores dos ministros e alguns outros economistas ligados ao governo.

Defendi a idéia de que os economistas foram apresentados em diversas ocasiões para justificar alguma medida econômica frente a críticas. U sando quase sempre 0 argumento do conhecimento científico e especializado, foram qualificados como técnicos pelas revistas, e seus argumentos freqüentemente afirmavam que não era possível, por exemplo, fazer política ou distribuir renda com as medidas econômicas, embora concordassem que tais atitudes fossem desejadas por todos (inclusive por eles próprios, segundo diziam). Foram os argumentos deles - mais do que os de Sarney ou dos ministros - que apareceram respondendo aos comentários a respeito do plano, viessem estes de políticos, empresários, sindicalistas ou cidadãos. Por sua vez, Sarney, Funaro e Sayad, entre outros, faziam a defesa política do plano percorrendo o Brasil e falando às mais variadas platéias - em auditórios, cerimônias, na TV ou até mesmo nas ruas. Funaro, inclusive, foi apresentado como um caso inédito: um ministro da Fazenda popular, que buscava o bem do povo e do país 17 . Essa união de esforços teceu uma rede de consenso em torno de determinados valores, legitimando aquele líder, aquele ministério e aqueles técnicos como os mais capacitados a enfrentar o que foi apontado como o grande inimigo que pairava sobre a sociedade brasileira: a inflação.

A segunda parte do texto buscou compreender melhor este processo de produção de sentido a partir de discussões sobre os intelectuais, com ênfase nas relações entre eles e a mídia, particularmente 0 jornalismo.

\section{Referências Bibliográficas}

BO BBIO , Norberto (1997). O s intelectuais e o poder. São Paulo: U nesp.

BO U RDIEU, Pierre (1998). A economia das trocas simbólicas. Sergio M iceli (in-trod., org., seleção). 5 edição. São Paulo: Perspectiva. p. 183-202. 
Carta ao Leitor [editorial]. Veja n. 913, 05/03/1986, p. 19.

G RAM SCI, A ntonio (1989). O s intelectuais e a organização da cultura. 7a edição. Trad. de Carlos Nelson Coutinho. Rio de Janeiro: Civilização Brasileira. p. 3-23.

MANSO, Guilherme da Costa.0 governo é de Sarney - entrevista de Almir Pazzianotto. São Paulo, Veja, n.913/ 05 de março, p.6.

MARANHÃO, Aluizio \& SELEME, Ascânio (1986). A musa dos cruzados. São Paulo. Istoé, n. 482/19 de março.

MATO S, Jaime \& O LIVEIRA, Ribamar (1986). Pacote de risco. Revista Istoé. São Paulo, n. 480/05 de M arço.

M ATO S, Jaime \& O LIVEIRA, Ribamar (1986). Solução a prazo. Revista Istoé. São Paulo, n. 481/12 de M arço.

MORAES, Dênis de (1998). Notas sobre o imaginário social e hegemonia cultural. Artigo publicado no sítio Gramsci e o Brasil. http:// www.artnet.com.br/gramsci/arquiv4 4.htm. Acesso em $12 / 10 / 2002$.

N O GUEIRA, Paulo (1986). São Paulo, Veja, n.916/ 26 de março.

N O GUEIRA, M arco A urélio (2000). Inventores do futuro: notas sobre os intelectuais, a política e a vida. Revista Z, Programa A vançado de Cultura Contemporânea, UFRJ, n. 3. http://acd.ufrj.br/pacc/ z/rever/3/ensaios/marco.html. A cesso em 12/10/2002.

SAID, Edward W. (1996). Representaciones del intelectual. Barcelona: Paidós. p. 23-58.

SARLO, Beatriz (2000). Cenas da vida pós-moderna. Rio de Janeiro: Editora UFRJ.

SO LNIK, Alex (1987). O s pais do Cruzado contam por que não deu certo. $L \& P M$ : Porto Alegre. 